\title{
Synthesis and Characterization of Novel Aromatic Polyamides from 3,4-Bis(4-aminophenyl)-2,5-diphenylthiophene and Aromatic Dicarboxylic Acids
}

\author{
Hwa-Jin Jeong, Atsushi Kobayashi, Masa-aki Kakimoto, \\ and Yoshio IMAI* \\ Department of Organic and Polymeric Materials, \\ Tokyo Institute of Technology, Meguro-ku, \\ Tokyo 152, Japan
}

(Received August 5, 1993)

\begin{abstract}
A new highly phenylated diamine, 3,4-bis(4-aminophenyl)-2,5-diphenylthiophene, was synthesized in three steps starting from 4'-nitrodeoxybenzoin. New aromatic polyamides containing tetraphenylthiophene unit were prepared by the low temperature solution polycondensation of this diamine with various aromatic dicarboxylic acid chlorides. These polyamides had inherent viscosities of $0.20-0.35 \mathrm{dlg}^{-1}$ and were generally soluble in various organic solvents such as $N, N$-dimethylacetamide, $N$-methyl-2-pyrrolidone, and dimethyl sulfoxide. The glass transition temperatures of the polyamides ranged from 285 to $327^{\circ} \mathrm{C}$, and the $10 \%$ weight loss temperatures were observed above $530^{\circ} \mathrm{C}$ in nitrogen.
\end{abstract}

KEY WORDS High Temperature Polymers / Soluble Aromatic Polyamides / 3,4-Bis(4-aminophenyl)-2,5-diphenylthiophene / Thermal Behavior /

Aromatic polyamides are well known to have high thermal stability coupled with high crystallinity and hence found high temperature applications especially as fibers for many years. $^{1}$ However, most wholly aromatic polyamides are difficult to fabricate because of their less solubility and high melting temperatures. Several attempts have been made to improve the solubility by modifying the structure without losing their good thermal stability. ${ }^{2,3}$ We also have found that the aromatic polyamides having phenyl-pendant structures such as tetraphenylthiophene, ${ }^{4-6}$ tetraphenylfuran, ${ }^{7}$ tetraphenylpyrrole, ${ }^{8}$ tetraphenylethylene, ${ }^{9}$ triphenylamine, ${ }^{10}$ and triphenylphosphine,${ }^{11}$ have high thermal stability and good solubility in various organic solvents. In continuation to our studies on the synthesis of high temperature polymers, we aimed at the synthesis of a new diamine monomer, 3,4-bis(4- aminophenyl)-2,5-diphenylthiophene, and the resultant aromatic polyamides. This article deals with the synthesis and characterization of novel aromatic polyamides from this diamine and various aromatic dicarboxylic acid chlorides. The properties were compared with those of the structurally related polyamides derived from the isomeric diamine, 2,5-bis(4aminophenyl)-3,4-diphenylthiophene. ${ }^{5}$

\section{EXPERIMENTAL}

\section{Materials}

Isophthaloyl chloride (IVa), terephthaloyl chloride (IVb), 4,4'-biphenyldicarbonyl chloride (IVc), 2,6-naphthalenedicarbonyl chloride (IVd), 4,4'-oxybibenzoyl chloride (IVe), and 4,4'-sulfonyldibenzoyl chloride (IVf) were obtained commercially and purified by distillation under reduced pressure. $N$-methyl-2-

\footnotetext{
* To whom all correspondence should be addressed.
} 
pyrrolidone (NMP) was purified by vacuum distillation with calcium hydride.

\section{Monomer Synthesis}

3,4-Bis(4-nitrophenyl)-2,5-diphenylthiophene (II). 1,2-Bis(4-nitrophenyl)-1,2-dibenzoylethane (I) was prepared in $75 \%$ yield by the oxidative coupling of $4^{\prime}$-nitrodeoxybenzoin using sodium ethoxide and iodine according to the method reported previously. ${ }^{7}$

In a flask, $39.0 \mathrm{~g}(81 \mathrm{mmol})$ of compound I and $40.5 \mathrm{~g}$ (97 mmol) of 2,4-bis(4-methoxyphenyl)-1,3-dithia-2,4-diphosphetane-2,4disulfide, Lawesson's reagent, were dissolved in $200 \mathrm{ml}$ of dry toluene and the mixture was refluxed for $5 \mathrm{~h}$. After cooling, the precipitate was removed by filtration, and the filtrate was evaporated to dryness under reduced pressure. The crude product was recrystallized from acetic acid to afford yellow prisms; mp $231-232^{\circ} \mathrm{C}$. The yield was $32.5 \mathrm{~g}(83 \%)$. The IR spectrum $(\mathrm{KBr})$ exhibited an absorption band at $1444 \mathrm{~cm}^{-1}$ (thiophene ring) with no carbonyl absorption. The ${ }^{13} \mathrm{C}$ NMR spectrum ( $\delta$ in $\mathrm{CDCl}_{3}$ ) showed peaks at $146.9,142.9$, $141.3,136.5,132.9,131.8,129.4,128.8,128.3$, and $123.5 \mathrm{ppm}$.

Anal. Calcd for $\mathrm{C}_{28} \mathrm{H}_{18} \mathrm{~N}_{2} \mathrm{O}_{4} \mathrm{~S}: \mathrm{C}, 70.28 \%$; $\mathrm{H}, 3.79 \%$; N, $5.85 \%$; S, 6.70\%. Found: C, $70.19 \%$; H, 3.66\%; N, 5.78\%; S, 6.55\%.

3,4-Bis(4-aminophenyl)-2,5-diphenylthiophene (III). To a mixture of $20.0 \mathrm{~g}(0.04 \mathrm{~mol})$ of compound II in $200 \mathrm{ml}$ of glacial acetic acid, a solution of $99.5 \mathrm{~g}(0.44 \mathrm{~mol})$ of stannous chloride dihydrate in $100 \mathrm{ml}$ of concentrated hydrochloric acid was added all at once. The mixture was refluxed for $5 \mathrm{~h}$. After it had been cooled, an aqueous sodium hydroxide solution was added to the resulting suspension with vigorous stirring in order to make a strongly alkaline mixture ( $\mathrm{pH} 11-12)$. The solid thus obtained was filtered, washed repeatedly with water, and dried. It was recrystallized from toluene to give white needles; $\mathrm{mp} 246-247^{\circ} \mathrm{C}$. The yield was $12.4 \mathrm{~g}(71 \%)$. The IR spectrum $(\mathrm{KBr})$ exhibited absorption bands at 3446 and
$3364 \mathrm{~cm}^{-1}(\mathrm{~N}-\mathrm{H})$. The ${ }^{1} \mathrm{H}$ NMR spectrum $[\delta$ in dimethyl sulfoxide (DMSO)- $\left.d_{6}\right]$ showed signals at $6.30-6.47(\mathrm{~d}, 4 \mathrm{H}$, aromatic ortho to $\left.\mathrm{NH}_{2}\right), 6.58-6.71(\mathrm{~d}, 4 \mathrm{H}$, aromatic meta to $\left.\mathrm{NH}_{2}\right)$, and $7.18-7.33 \mathrm{ppm}(\mathrm{m}, 14 \mathrm{H}$, other aromatic). The ${ }^{13} \mathrm{C}$ NMR spectrum $(\delta$ in DMSO- $d_{6}$ ) exhibited peaks at $148.2,141.8$, $137.3,135.6,132.2,129.7,129.5,128.1,124.8$, and $114.8 \mathrm{ppm}$.

Anal. Calcd for $\mathrm{C}_{28} \mathrm{H}_{22} \mathrm{~N}_{2} \mathrm{~S}: \mathrm{C}, 80.35 \% ; \mathrm{H}$, $5.30 \%$; N, 6.69\%; S, 7.66\%. Found: C, $80.56 \%$; H, 5.37\%; N, 6.52\%; S, 7.44\%.

\section{Polymerization}

A typical example of the polycondensation is given below.

\section{Polyamide Vb from III and IVb}

In a three neck flask, a solution of $1.046 \mathrm{~g}$ $(2.5 \mathrm{mmol})$ of diamine III and $5.0 \mathrm{ml}$ of NMP was chilled in a dry ice-acetone bath under nitrogen. To this, $0.508 \mathrm{~g}(2.5 \mathrm{mmol})$ of solid diacid chloride $\mathbf{I V b}$ was added all at once. Then the mixture was stirred at $4^{\circ} \mathrm{C}$ in an ice-water bath. The polymerization proceeded as the solid dissolved. After stirring at that temperature for $5 \mathrm{~h}$, the reaction mixture was poured into $400 \mathrm{ml}$ of methanol. The precipitated polymer was collected, washed thoroughly with methanol, and dried at $100^{\circ} \mathrm{C}$ under vacuum. The yield was $1.340 \mathrm{~g}(97 \%)$. The inherent viscosity of the polymer in concentrated sulfuric acid was $0.23 \mathrm{dlg}^{-1}$, measured at a concentration of $0.5^{\circ} \mathrm{g} \mathrm{dl}^{-1}$ at $30^{\circ} \mathrm{C}$. The IR spectrum (film) exhibited absorption bands at $3380 \mathrm{~cm}^{-1}(\mathrm{~N}-\mathrm{H})$ and $1657 \mathrm{~cm}^{-1}(\mathrm{C}=\mathrm{O})$.

Anal. Calcd for $\left(\mathrm{C}_{36} \mathrm{H}_{24} \mathrm{~N}_{2} \mathrm{O}_{2} \mathrm{~S}\right)_{n}$ : C, $78.81 \%$; H, $4.41 \%$; N, $5.11 \%$; S, $5.84 \%$. Found: C, 78.49\%; H, 4.53\%; N, 5.21\%; S, $5.61 \%$.

\section{Measurements}

IR spectra were recorded on a JASCO FTIR-5000 spectrophotometer. ${ }^{1} \mathrm{H}$ NMR (90 MHz) and ${ }^{13} \mathrm{C}$ NMR $(22.6 \mathrm{MHz})$ spectra were obtained on a JEOL C60-HL spectrom- 
eter. Wide angle X-ray diffraction patterns were obtained for film specimens on a Rigaku Denki XG X-ray diffraction apparatus with nickel-filtered $\mathrm{Cu}-K_{\alpha}$ radiation $(35 \mathrm{kV}, 200 \mathrm{~mA})$. Differential thermal analysis (DTA), thermogravimetry (TG), and differential scanning calorimetry (DSC) were performed with Shimadzu thermal analyzers DTA-40, TGA$40 \mathrm{M}$, and DSC-41M, respectively, and the measurements were made at a heating rate of $10^{\circ} \mathrm{C} \mathrm{min}^{-1}$ in air or nitrogen.

\section{RESULTS AND DISCUSSION}

\section{Monomer Synthesis}

A new aromatic diamine having bulky pendant phenyl groups, 3,4-bis(4-aminophenyl)2,5-diphenylthiophene (III), was synthesized in three steps starting from $4^{\prime}$-nitrodeoxybenzoin according to eq 1 .

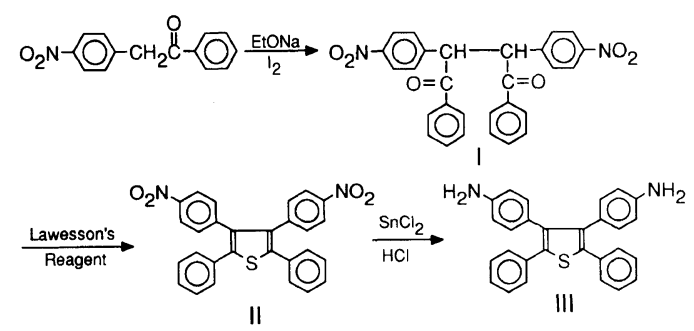

Recently Lawesson's reagent, 2,4-bis(4-methoxyphenyl)-1,3-dithia-2,4-diphosphetane2,4-disulfide, was used effectively in place of classic phosphorus pentasulfide as a sulfurizing agent for the synthesis of substituted thiophenes from 1,4-diketone compounds. ${ }^{12}$ Here compound I, synthesized by the oxidative coupling of $4^{\prime}$-deoxybenzoin, ${ }^{7}$ was successfully converted by treating with Lawesson's reagent in refluxing toluene to 3,4bis(4-nitrophenyl)-2,5-diphenylthiophene (II) in $83 \%$ yield. The subsequent reduction of the dinitro compound II with stannous chloride afforded diaminotetraphenylthiophene III in $71 \%$ yield.

The chemical structures of all the synthesized compounds were confirmed by means of both IR and NMR spectra, and elemental analysis. Concerning the synthesis of compound II, the disappearance of the characteristic carbonyl band at $1660 \mathrm{~cm}^{-1}$ was observed on the IR spectrum together with the appearance of an absorption band at $1444 \mathrm{~cm}^{-1}$ due to thiophene ring. Compound III showed IR absorptions at 3446 and $3364 \mathrm{~cm}^{-1}$ characteristic of amino group. The ${ }^{13} \mathrm{C}$ NMR spectrum of compound III exhibited 10 peaks due to symmetry, indicative of the formation of the postulated diamine. The elemental analysis of all of these compounds were also in good agreement with the calculated values for the proposed structures.

\section{Polymer Synthesis}

New aromatic polyamides $\mathbf{V}$ containing tetraphenylthiopene unit were prepared by the low temperature solution polycondensation of diaminotetraphenylthiophene III with various aromatic dicarboxylic acid chlorides IVa-IVf in NMP [eq 2].

The results of synthesis of the aromatic polyamides are summarized in Table I. The inherent viscosities of the polymers were in the

Table I. Synthesis of aromatic polyamides ${ }^{\mathrm{a}}$

\begin{tabular}{|c|c|c|c|c|}
\hline \multirow{3}{*}{$\begin{array}{l}\text { Diacid } \\
\text { chloride }\end{array}$} & \multicolumn{3}{|c|}{ Polymer } & \multirow{3}{*}{ Remarks $^{c}$} \\
\hline & \multirow{2}{*}{ Code } & Yield & $\eta_{\text {inh }}^{\mathrm{b}}$ & \\
\hline & & $\%$ & $\mathrm{dl} \mathrm{g}^{-1}$ & \\
\hline IVa & $\mathbf{V a}$ & 99 & 0.20 & S \\
\hline IVb & $\mathbf{V b}$ & 82 & 0.20 & $\mathbf{P}$ \\
\hline IVc & Vc & 89 & 0.33 & S \\
\hline IVd & Vd & 95 & 0.35 & S \\
\hline IVe & Ve & 86 & 0.27 & $\mathrm{~S}$ \\
\hline IVf & Vf & 90 & 0.30 & $\mathbf{S}$ \\
\hline
\end{tabular}

a Polymerization was carrried out with $2.5 \mathrm{mmol}$ of each monomer in $5.0 \mathrm{ml}$ of $\mathrm{NMP}$ at $4^{\circ} \mathrm{C}$ for $5 \mathrm{~h}$ under nitrogen

b Measured at a concentration of $0.5 \mathrm{~g} \mathrm{dl}^{-1}$ in concentrated sulfuric acid at $30^{\circ} \mathrm{C}$.

c Appearance of the polymerization mixture: S, homogeneous solution; $\mathrm{P}$, polymer precipitation. 
range of $0.20-0.35 \mathrm{dlg}^{-1}$, and hence these polyamides gave brittle films by

$$
\begin{aligned}
& \text { O) } \\
& \text { III } \\
& \text { IV } \\
& \stackrel{-H C}{\longrightarrow}
\end{aligned}
$$

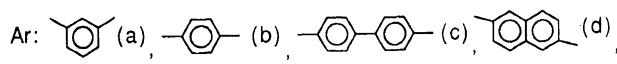

$$
\begin{aligned}
& \text {-(0) }- \text { - (O) }-(\mathrm{e})-(\mathrm{O})-\mathrm{SO}_{2}-(\mathrm{O})-(\mathrm{t})
\end{aligned}
$$

casting from the NMP solutions. Most of the polycondensations proceeded in homogeneous solution, except the polymerization with IVb where precipitation of the polymer occurred during the course of the reaction because of low solubility of polymer Vb in NMP. On the whole, this diaminotetraphenylthiophene afforded the polymers with relatively low viscosity values, compared with polyamides VI having inherent viscosities of around $1.0 \mathrm{dl} \mathrm{g}^{-1}$ derived from the isomeric diamine, 2,5-bis(4aminophenyl)-3,4-diphenylthiophene. ${ }^{5}$ The reason is unclear yet, but may be attributed partly to the steric hindrance of diamine III with V-shaped narrow angle between two aminophenyl groups. The IR spectra of these polymers showed characteristic amide absorption bands at around $3360 \mathrm{~cm}^{-1}(\mathrm{~N}-\mathrm{H})$ and $1657 \mathrm{~cm}^{-1}(\mathrm{C}=\mathrm{O})$, which confirmed the formation of the proposed polyamides.

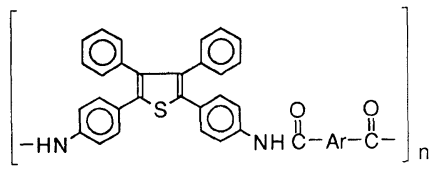

VI

\section{Polymer Characterization}

Table II lists qualitative solubility of the
Table II. Solubility of aromatic polyamides ${ }^{a}$

\begin{tabular}{llllll}
\hline \multirow{2}{*}{ Solvent } & \multicolumn{5}{c}{ Polymer } \\
\cline { 2 - 5 } & Va & Vb, Vd & Vc & Ve, Vf \\
\hline$N$-Methyl-2-pyrrolidone & ++ & ++ & ++ & ++ \\
$N, N$-Dimethylacetamide & ++ & + & ++ & ++ \\
$m$-Cresol & ++ & - & - & + \\
Pyridine & ++ & - & - & ++ \\
\hline
\end{tabular}

a Solubility: ++ , soluble at room temperature; + , soluble on heating; - insoluble.

tetraphenylthiophene-containing aromatic polyamides $\mathbf{V}$. All the polymers were soluble in NMP, N,N-dimethylacetamide, and dimethyl sulfoxide, but entirely insoluble in methanol, acetone, and chloroform. Polymer Va with $m$-phenylene moiety as well as polymers Ve and Vf having flexible connecting groups were more soluble than the other polymers (Vb, Vc, and $\mathbf{V d}$ ) with rigid symmetric structures, and dissolved even in $m$-cresol and pyridine. Polyamides VI having isomeric structure (the arylene moiety (Ar) for polymer VI corresponds individually to that for polymer V) showed similar solubility behavior to the present polyamides $\mathbf{V}$. The solubility of these two tetraphenylthiophene-based polyamides was better than that of the tetraphenylfuranand tetraphenylpyrrole-containing polyamides. $^{7,8}$

The thermal behavior of these polyamides $\mathbf{V}$ and VI was evaluated by means of DTA, TG, and DSC. Figure 1 shows typical DTA and TG curves of polyamide $\mathbf{V a}$, and the glass transition temperatures $\left(T_{\mathrm{g}}\right)$ and $10 \%$ weight loss temperatures $\left(T_{10}\right)$ are summarized in Table III. The present polyamides $\mathbf{V}$ had relatively high $T_{\mathrm{g}}$ values in the range of $285-327^{\circ} \mathrm{C}$. In general, polyamides $\mathrm{Vb}$ and $\mathrm{Vc}$ having rigid symmetric structures had higher $T_{\mathrm{g}}$ values than polymers $\mathrm{Va}$ with unsymmetric one. On the whole, the $T_{\mathrm{g}}$ values were almost comparable to those of the isomeric polyamides VI $\left(304-317^{\circ} \mathrm{C}\right)$, and even to those of tetraphenylfuran- and tetraphenylpyrrole-con- 


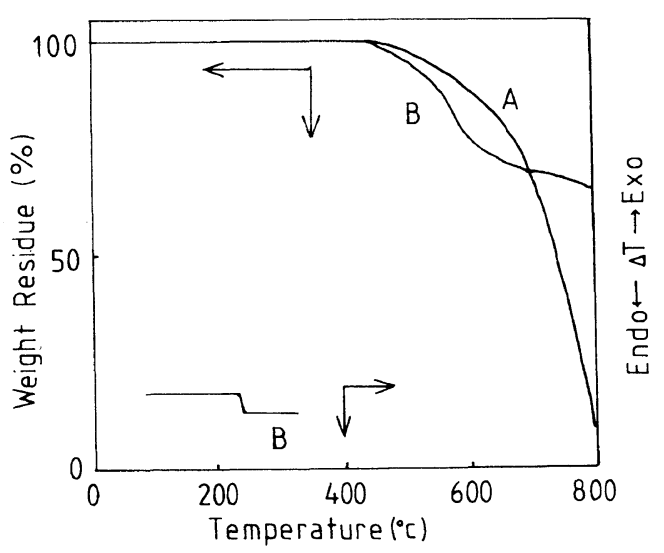

Figure 1. DTA and TG curves for polyamide Va at a heating rate of $10^{\circ} \mathrm{Cmin}^{-1}$ in (A) air and (B) nitrogen.

Table III. Thermal behavior of aromatic polyamides

\begin{tabular}{|c|c|c|c|c|}
\hline \multirow{4}{*}{ Polymer } & \multirow{4}{*}{$\frac{T_{\mathrm{g}}^{\mathrm{a}}}{{ }^{\circ} \mathrm{C}}$} & \multicolumn{2}{|c|}{$T_{10}{ }^{\mathrm{b}}$} & \multirow{4}{*}{$\frac{\text { Char yield }^{\mathrm{c}}}{\%}$} \\
\hline & & \multirow{3}{*}{$\frac{\text { In air }}{{ }^{\circ} \mathrm{C}}$} & \multirow{3}{*}{$\frac{\text { In nitrogen }}{{ }^{\circ} \mathrm{C}}$} & \\
\hline & & & & \\
\hline & & & & \\
\hline $\mathbf{V a}$ & 29.3 & 565 & 535 & 64 \\
\hline $\mathbf{V b}$ & 323 & 510 & 565 & 65 \\
\hline Ve & 321 & 505 & 545 & 62 \\
\hline Vd & 299 & 530 & 560 & 64 \\
\hline Ve & 285 & 510 & 540 & 60 \\
\hline Vf & 327 & 490 & 530 & 57 \\
\hline VIa & 304 & 490 & 500 & 39 \\
\hline VIb & 314 & 500 & 530 & 55 \\
\hline VIc & - & 535 & 540 & 58 \\
\hline VId & - & 505 & 565 & 78 \\
\hline VIe & 306 & 495 & 515 & 49 \\
\hline VIf & 317 & 475 & 510 & 59 \\
\hline
\end{tabular}

a Determined by DSC in nitrogen at a heating rate of $10^{\circ} \mathrm{Cmin}^{-1}$.

b Temperature at which $10 \%$ weight loss was recorded by TG at a heating rate of $10^{\circ} \mathrm{Cmin}^{-1}$.

c Char yield in nitrogen at $800^{\circ} \mathrm{C}$.

taining polyamides. ${ }^{7,8}$

All the present polyamides $\mathbf{V}$ did not lose weight below $400^{\circ} \mathrm{C}$ in air or nitrogen, and the $T_{10}$ values in air and nitrogen were in the range of $490-565^{\circ} \mathrm{C}$ and $530-565^{\circ} \mathrm{C}$, respectively, indicating high thermal stability. In addition, more than $60 \%$ weight was retained even at $800^{\circ} \mathrm{C}$ in nitrogen for these polyamides. The thermal stability with respect to $T_{10}$ values was somewhat higher than that of the isomeric polyamides VI. On the basis of $T_{10}$ values in air or nitrogen, these tetraphenylthiophenebased polyamides had higher thermal stability than the tetraphenylfuran- and tetraphenylpyrrole-containing polyamides. ${ }^{7,8}$ This is attributable to difference in inherent thermal stability between these five-membered heterocyclic rings as discussed previously. ${ }^{8}$

\section{CONCLUSION}

We have synthesized the new aromatic diamine having bulky pendant phenyl groups, 3,4-bis(4-aminophenyl)-2,5-diphenylthiophene, which was subjected to polycondensation with aromatic dicarboxylic acid chlorides giving new aromatic polyamides. These polyamides were soluble in various organic solvents, and had high glass transition temperatures as well as high thermal stability.

\section{REFERENCES}

1. P. E. Cassidy, "Thermally Stable Polymers," Dekker, New York, N.Y., 1980.

2. F. Akutsu, H. Hayashi, M. Miura, and K. Nagakubo, Makromol. Chem., Rapid Commun., 6, 475 (1985).

3. F. Akutsu, T. Kataoka, K. Naruchi, M. Miura, and K. Nagakubo, Polymer, 28, 1787 (1987).

4. M. Kakimoto, Y. S. Negi, and Y. Imai, J. Polym. Sci., Polym. Chem. Ed., 23, 1787 (1985).

5. Y. Imai, N. N. Maldar, and M. Kakimoto, J. Polym. Sci., Polym. Chem. Ed., 23, 1797 (1985).

6. Y. Imai and M. Kakimoto, Polym. Plast. Technol. Eng., 28, 371 (1989).

7. H.-J. Jeong, Y. Oishi, M. Kakimoto, and Y. Imai, J. Polym. Sci., A, Polym. Chem., 28, 3293 (1990).

8. H.-J. Jeong, M. Kakimoto, and Y. Imai, J. Polym. Sci., A, Polym. Chem., 29, 767 (1991).

9. M.-L. Xie, Y. Oishi, M. Kakimoto, and Y. Imai, $J$. Polym. Sci., A, Polym. Chem., 29, 55 (1991).

10. Y. Oishi, H. Takado, M. Yoneyama, M. Kakimoto, and Y. Imai, J. Polym. Sci., A, Polym. Chem., 28, 1763 (1990).

11. M. Yamashita, M. Kakimoto, and Y. Imai, J. Polym. Sci., A, Polym. Chem., 31, 1513 (1993).

12. D. R. Shridhar, M. Jogibhukta, P. S. Rao, and V. K. Handa, Synthesis, 1061 (1982). 